\title{
HIGH STRENGTH HIP CONSOLIDATED MERL 76 DISKS
}

\author{
by \\ R. D. Eng and D. J. Evans \\ Material Engineering Research Laboratory \\ Pratt \& Whitney Aircraft Group \\ East Hartford, Connecticut 06108
}

\begin{abstract}
ABSTR ACT
Disk consolidations, $66 \mathrm{~cm}$ diameter weighing $318 \mathrm{~kg}$, were manufactured from the powder metal alloy MERL 76. HIP consolidation parameters were established at $1182^{\circ} \mathrm{C} / 103 \mathrm{MPa} / 3$ hours to give improved notch rupture lives while maintaining tensile properties. A multi-step heat treatment $-1163^{\circ} \mathrm{C} / 2$ hours $/ O Q+$ $871^{\circ} \mathrm{C} / .67$ hours $/ \mathrm{AC}+992^{\circ} \mathrm{C} / .75$ hours $/ \mathrm{AC}+649^{\circ} \mathrm{C} / 16$ hours $/ A C+760^{\circ} \mathrm{C} / 16$ hours $/ A C$ - was selected.

Based on the demonstrated ability to process full-size disks in a production environment and on mechanical properties of material from various locations of full-size disks meeting target goals, the alloy can be committed to component spin/burst testing and land-based experimental engine testing can be conducted prior to production incorporation.
\end{abstract}

\section{INTRODUCTION}

The demand for improved performance in gas turbine engines has provided the impetus to develop advanced materials technologies. Better engine performance can be achieved, for example, by raising operating loads and temperatures of turbine disks. Materials with improved tensile properties to permit higher rotational spceds and creep rupture capability to accomodate the increased temperatures are now required. This new strength goal for nickel-base superalloys can be achieved by increasing the hardener ( $\mathrm{Al}, \mathrm{Ti}, \mathrm{Hf}, \mathrm{Cb})$ content. However, this causes extensive segregation in cast ingots resulting in an unforgeable product. This problem has been circumvented by employing hot isostatic pressing (HIP) of powders, which has the further benefit of reducing the amount of strategic raw materials required to produce a component. 


\section{2 / Superalloys 1980}

In the mid-1970's, Pratt \& Whitney Aircraft defined an alloy composition specifically for fabrication by hot isostatic pressing into engine components, with mechanical properties equivalent to Gatorized@ IN-100(1). The IN-100 composition was modified by reducing carbon and adding hafnium and columbium for ductility and carbide control. Vanadium was eliminated for improved hot-corrosion resistance.

Much work remains after alloy selection prior to production incorporation of a new disk alloy. Container design must be verified and HIP consolidation limits defined. Post-HIP heat treatments must be established and extensive specimen and component testing conducted to set design allowables. Finally, engine demonstration and certification testing is conducted.

A significant portion of this material qualification effort is being conducted on a cooperative PWA/NASA program entitled Materials for Advanced Turbine Engines (MATE). The results of a portion of this program, as well as other process-related studies conducted at P\&WA, are reported in this paper.

\section{MANUFACTURE OF DISK CONSOLIDATIONS}

\section{Physical Metallurgy and Disk Processing}

The MERL 76 powder (Cr:12.5, Co:18.5, Mo:3.2, Al:5.0, Ti:4.4, Hf:0.4, Cb:1.4, B:0.02, $\mathrm{Zr}: 0.06$, $\mathrm{C}: 0.02$, Ni:R) was produced by inert gas and by hydrogen atomization for use in manufacturing full size HIP consolidated disks. The powder was dynamically degassed prior to loading into stainless steel disk containers, hot degassed under vacuum, and sealed. During the development of the MERL 76 composition, it was observed that a slight variation in the hafnium content had substantial effects on the HIP

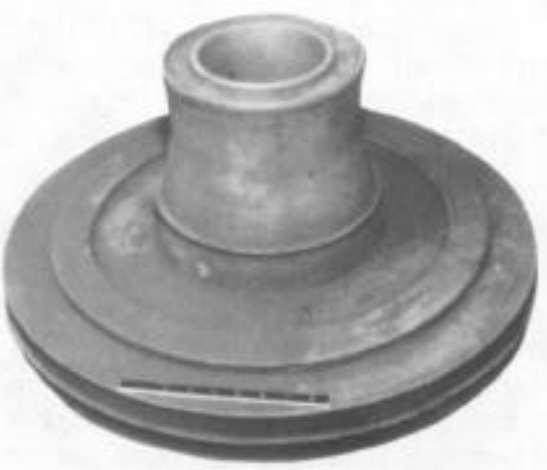

Fig. 1 JT10D HPT Disk Weighing $318 \mathrm{Kg}$. processing of the alloy. Decreasing the hafnium content from 0.7 to 0.4 weight percent increased the incipient melting point by $18^{\circ} \mathrm{C}$ to $1210^{\circ} \mathrm{C}$ while the gamma prime solvus remained essentially the same at $1191^{\circ} \mathrm{C}$. The hafnium affects the size and volume fraction of gamma prime, 
as well as solutioning rate, permitting grain size control by selection of process temperatures relative to the volume fraction of gamma-prime present. HIP consolidation temperature $18^{\circ} \mathrm{C}$ below the gamma prime solvus will yield a grain size of ASTM 10-12 while $12^{\circ} \mathrm{C}$ above would yield ASTM 6-8. A HIP consolidation temperature $9^{\circ} \mathrm{C}$ below the gamma prime solvus would give an intermediate ASTM 8-10 grain size. The HIP consolidation parameters of $1182^{\circ} \mathrm{C} / 103 \mathrm{MPa} / 3$ hours were selected to give such an intermediate grain size, resulting in improved notch rupture lives while maintaining tensile properties. A typical disk, about $66 \mathrm{~cm}$ in diameter, is shown in Figure 1.

The as-HIP microstructure is given in Figure $2 a$, showing a grain size of ASTM 8-10. Because of the relatively slow cooling rate from the $1182^{\circ} \mathrm{C}$ HIP temperature, the as-HIP microstructure contains extremely coarse gamma prime particles ranging from $2.5 \mu \mathrm{m}$ in the matrix to as large as $10 \mu \mathrm{m}$ in the grain boundaries (Figure 2). This gamma prime phase imparts strength to the alloy by precipitation of as much as 60 volume percent in the fully aged condition. A small number of MC-type carbides, typically containing hafnium, columbium, and titanium are also present in the alloy. As a result, thermal processing of the disks is required to provide a more suitable microstructure for meeting the target $0.2 \%$ yield strength goal of 965 $\mathrm{MPa}$ and ultimate strength of $1337 \mathrm{MPa}$ at $620^{\circ} \mathrm{C}$.
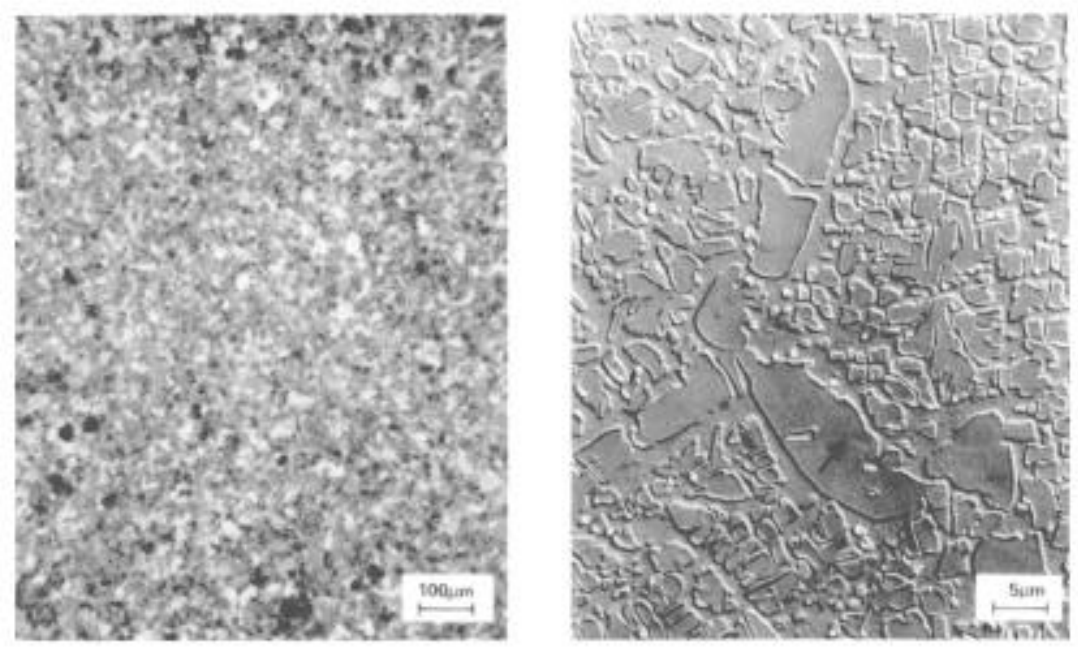

Fig. 2 As-HIP Mierostructure Showing a Grain Size of ASTM 8-10. 


\section{Selection of Heat Treatment}

To establish the required tensile, creep and rupture behavior in the HIP consolidated disks, it is required to modify the coarse, overaged gamma-prime resulting from the slow cool in the HIP cycle. This is accomplished by an elevated temperature solution treatment at a temperature below the gamma prime solvus followed by rapid quenching. The disks are then given one or more intermediate temperature precipitation heat treatments.

An evaluation of both solution heat treatment and precipitation strengthening cycles was conducted to maximize the material tensile strength while also providing good notch rupture properties. Comparative tensile and smooth/notch rupture testing of material removed from the full-size disk components weighing $381 \mathrm{~kg}$ were used for this heat treal evaluation.

The first disk was segmented into quarters and given various cooling rates from the $1163^{\circ} \mathrm{C} / 2$ hours solution heat treatment. The following cooling sequences were used: oil bath quenching, $163^{\circ} \mathrm{C}$ salt bath quenching, $343^{\circ} \mathrm{C}$ salt bath quenching, and air cooling. Following solution heat treating, a two-step precipitation treatment of $649^{\circ} \mathrm{C} / 24$ hours $/ \mathrm{AC}+760^{\circ} \mathrm{C} / 16$ hours/AC was applied to each section. Tensile test results, as shown in Figure 3, indicated that

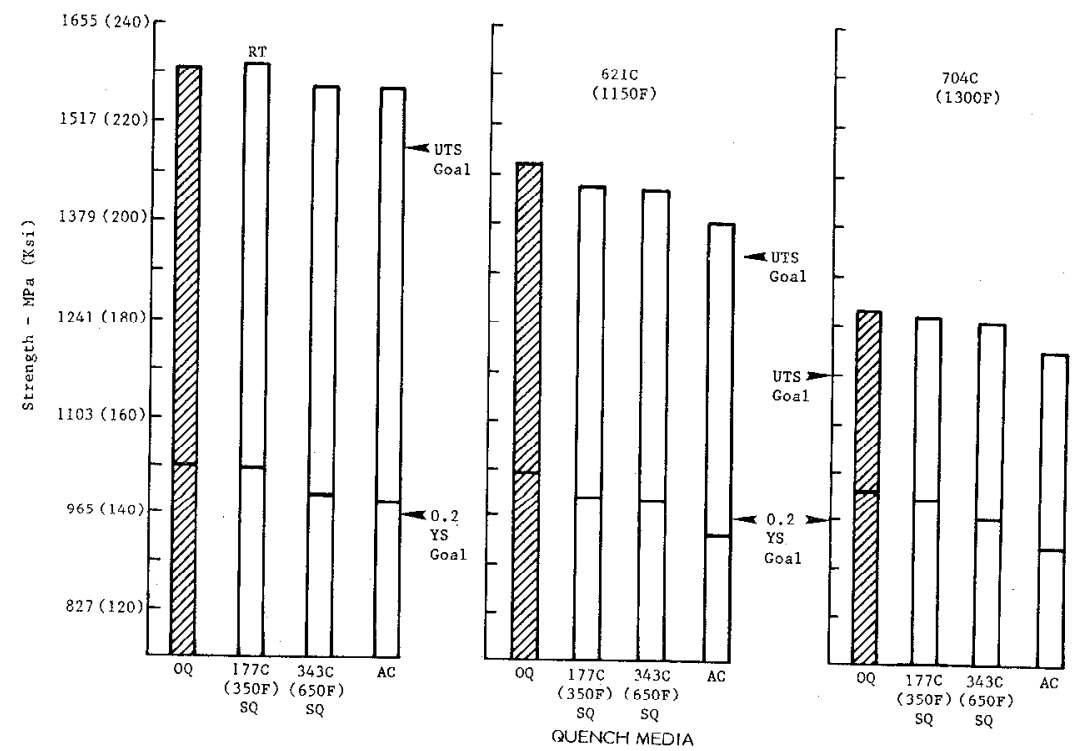

Fig. 3 Tensile Properties of Material Given Various Quench Sequences From $1163^{\circ} \mathrm{C} / 2$ Hours and Then Aged at $649^{\circ} \mathrm{C} / 24+760^{\circ} \mathrm{C} / 16$. 
material given an oil quench displayed the highest strengths while maintaining tensile duetility comparable to the other cooling rates. Notch stress-rupture lives ranging from 12-35 hours were measured for all material conditions.

Metallographic examination was performed to determine the effect of cooling rate on microstructure and the influence of the solution heat treatment. Microstructural analysis revealed that the precipitation of gramma prime which oceurred during cooling from solution treatment was coarser for material given a foreed air cool $(0.5 \mu \mathrm{m})$, than material given either a $163^{\circ} \mathrm{C}$ salt bath quench or an oil bath quench $(0.1 \mu \mathrm{m})$, as shown by Figure 4 . Moreover, both solution heat treatments were effective in reducing the as-HIP matrix cooling gamma prime size from $2.5 \mu \mathrm{m}$ shown previously in Figure 2.
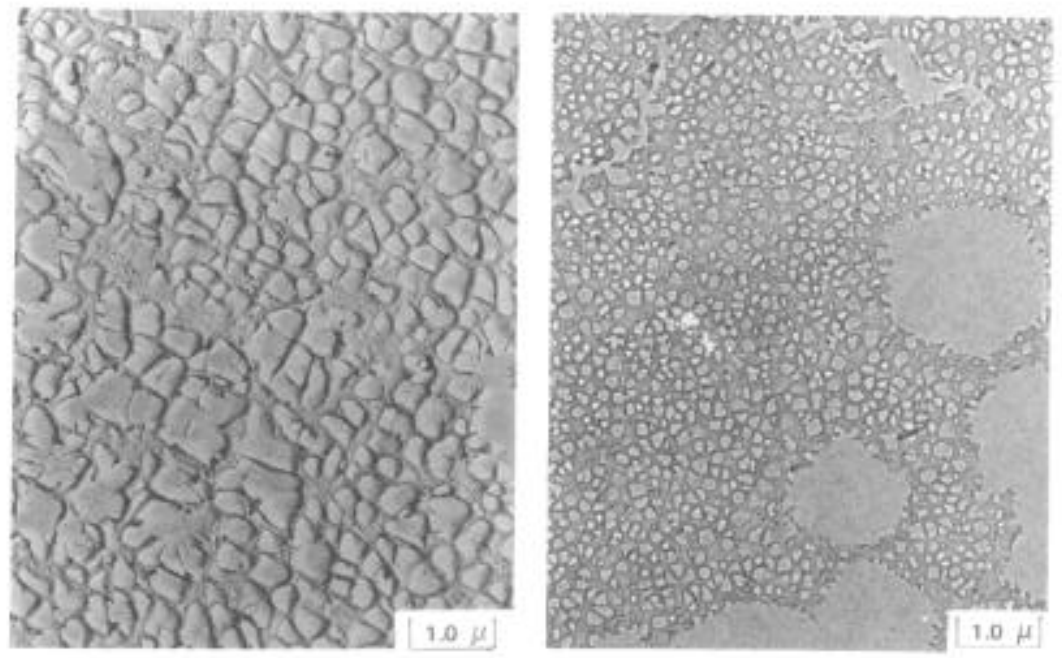

Fig. 4 Electron Micrographs of MERL 76 HIP Consolidation Heat Treated as Follows: Given an Air Cool (Left) and Oil Quench (Right).

The similarities in properties and microstructure between material given an oil bath quench and salt bath quench suggest that the cooling rates were similar. The equivalence of cooling rates for oil bath quenching and a $204^{\circ} \mathrm{C}$ salt bath quenching was also identified by P. S. Mathur, et al (2).

In order to achieve the best balance between strength and duetility, an evaluation of several multi-step heat treatments was conducted. Precipitation temperatures of $649-982^{\circ} \mathrm{C}$ and exposure 
times of up to $4 \overline{8}$ hours were evaluated. Blanks used for these heat treat evaluations were removed from a second disk, solution heat treated at $1163^{\circ} \mathrm{C} / 2$ hours $/ O Q$. Figure 5 summarizes the $621^{\circ} \mathrm{C}$ tensile strengths displayed after the various heat treat cycles. A $760^{\circ} \mathrm{C}$ age provided the highest ultimate and yield strength when compared to either the $788^{\circ} \mathrm{C}$ or $816^{\circ} \mathrm{C}$ aging cycle. The strength was further increased by $35 \mathrm{MPa}$ when the exposure time at $760^{\circ} \mathrm{C}$ was increased to 16 hours. Incorporating an intermediate exposure of $871^{\circ} \mathrm{C}$ and $982^{\circ} \mathrm{C}$ provided a stress relief cycle for the quenched material, without adversely affecting properties (Figure 5c). For the various age cycles evaluated, the tensile ductility ranged from 18-25\% while notch rupture lives ranged from $15-35$ hours. As a result, the heat treatment selected was $1163^{\circ} \mathrm{C} / 2$ hours $/ \mathrm{OQ}+871^{\circ} \mathrm{C} / .67$ hours $/ \mathrm{AC}+992^{\circ} \mathrm{C} / .75$ hours $/ \mathrm{AC}+649^{\circ} \mathrm{C} / 16$ hours/AC + $760^{\circ} \mathrm{C} / 16$ hours/AC.

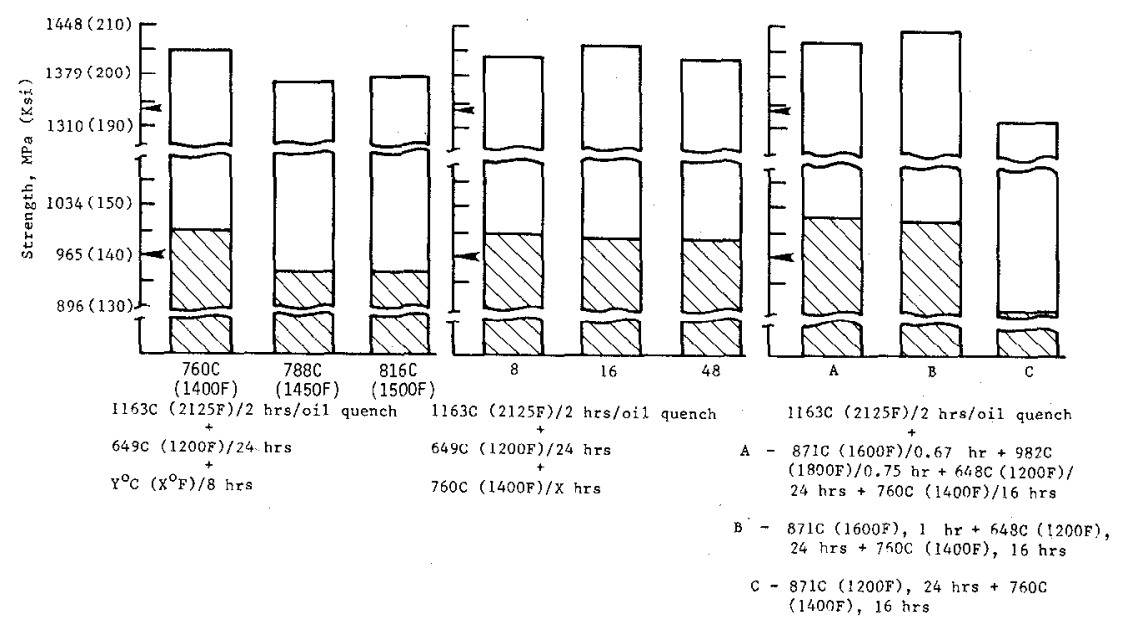

Fig. 5 Effect of Aging Cycle on $621^{\circ} \mathrm{C}$ Tensile Strength

Having identified a heat treatment which resulted in the gool properties being achieved, it remained to verify them on full scale disks. Such an evaluation is especially important since the effect of varying disk thicknesses is to modify cooling rate from solution treatment, with resultant changes in property levels.

During the evaluation of a number of heats of MERL 76 powder, the fracture surface of specimens from one lot of HIP consolidated material displayed fracture along prior particle boundaries (Figure 6). X-ray energy spectroscopy identified these surfaces to be hafnium rich. The origin of these prior particle boundaries was traced to a 

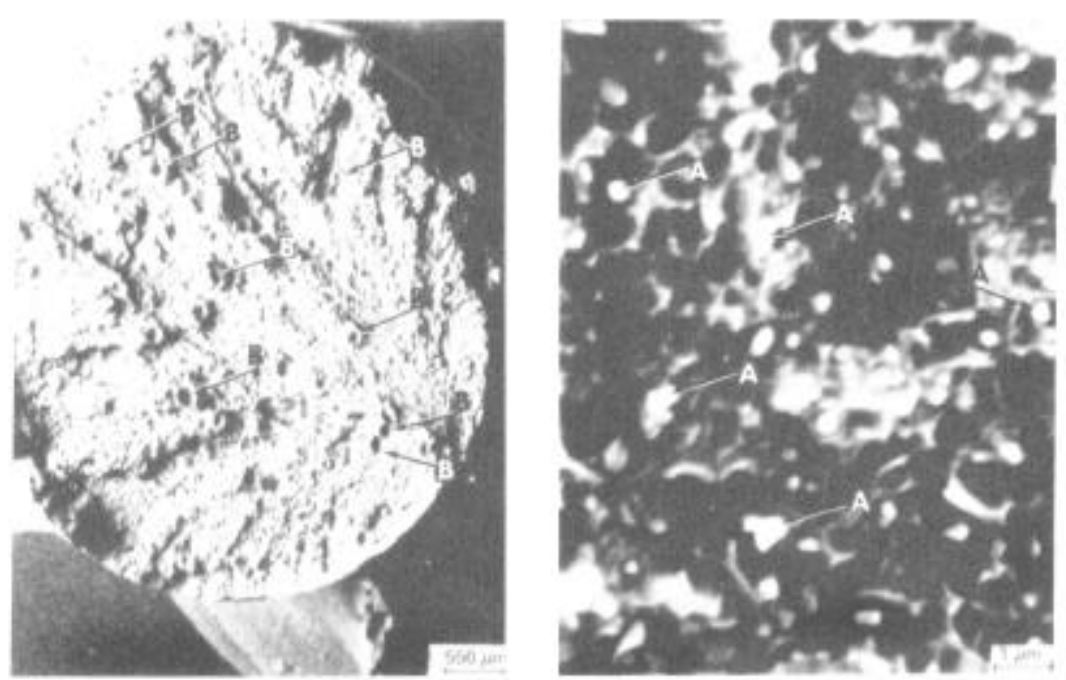

Fin. 6 X-ray Energy Spectroseopy Determined That Discrete Particles (A) (Right), Probably Hafnium Oxide, Decorate the Prior Particle Boundaries (B) (Left).

number of discolored powder particles, presumably hafnium oxide-coated, in the as-atomized heat of material. Chemical analysis of the powder and subsequent HIP consolidations indicated that target content was closely met. Furthermore, neither chemical analysis nor electron microprobe analysis was able to distinguish any difference between discolored particles and uncontaminated particles. Although furnace and material records were exhaustively analyzed, the specific cause of the discoloration of some of the particles in the as-atomized powder has not been determined.

Test results indicated that the contaminated powder debited the $732^{\circ} \mathrm{C}$ notch rupture life and $704^{\circ} \mathrm{C}$ tensile ductility only, while tensile and rupture properties below $704^{\circ} \mathrm{C}$ were not debited (Figure 7). Furthermore, Sonntag LCF properties in the temperature range of $427-635^{\circ} \mathrm{C}$ were unaffected by the contaminated particles.

Although the contaminated powder has resulted in reduced $732^{\circ} \mathrm{C}$ notch rupture life and $704^{\circ} \mathrm{C}$ tensile ductility, it may remain useful for up to $649^{\circ} \mathrm{C}$ service. Such material should be scrutinized before usage, since the effect of this type of contamination has not been quantified. Current process specifications must be altered to detect the occurrence of such contaminated powder early in the processing sequence and to avoid its use in critical part fabrication. Visual examination of samples of individual powder heats provides a good first-step monitoring. 

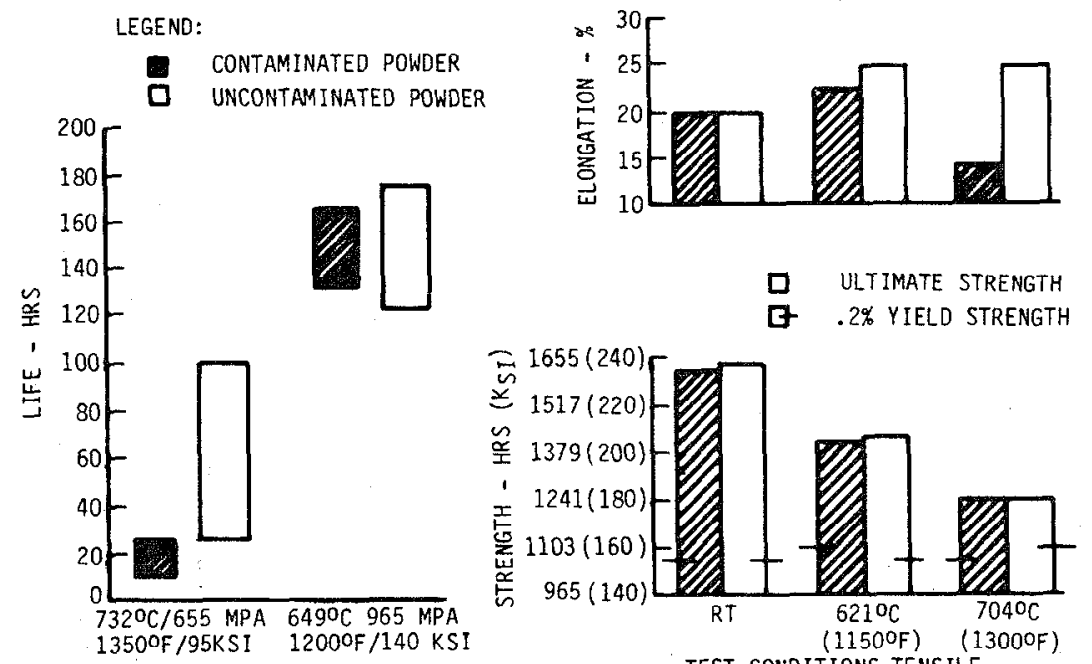

Fig. 7 Stress-Rupture and Tensile Properties Showing Contaminated Powder Reduces $732^{\circ} \mathrm{C}$ Notch Rupture Life and $704^{\circ} \mathrm{C}$ Tensile Ductility

\section{MECHANICAL PROPERTIES}

The complexity of thermal and mechanical stress gradients imposed upon the disk component during engine operation has caused designers to be particularly attentive to the mechanical properties of the alloy at various locations.

Tensile strength is an essential factor throughout the disk. For this reason, specimens representing two different section sizes were removed from several disk components. The specimens were removed from sections approximately $5 \mathrm{~cm}$ thick (e.g. rim, flange) and $10 \mathrm{~cm}$ thick (bore, web). Tensile results at $621{ }^{\circ} \mathrm{C}$ indicated that the thin section material was approximately $35 \mathrm{MPa}$ stronger than the thicker sections as shown in Figure 8. While tensile strength was affected by section size, ductility was not. Similar effects of section size were also observed for direct HIP low carbon Astroloy disk consolidations $(3)$.

Stress-rupture strength is generally the design concern at the rim of a turbine disk. Test results of combination notch/smooth stress-rupture specimens indicated that an average life of 45 hours and mixture of smooth and notch failure modes were achieved. Another important disk component property is low cycle fatigue. Sonntag testing was used to define the fatigue capability of MERL 76 
between $427^{\circ} \mathrm{C}$ and $635^{\circ} \mathrm{C}$ and with notch factors of $1.0,2.0$, and 3.0. Results are presented in Figures 9-11. Based upon extensive testing of material from various disk locations, target tensile and rupture property goals were met and Sonntag fatigue strengths were acceptable.

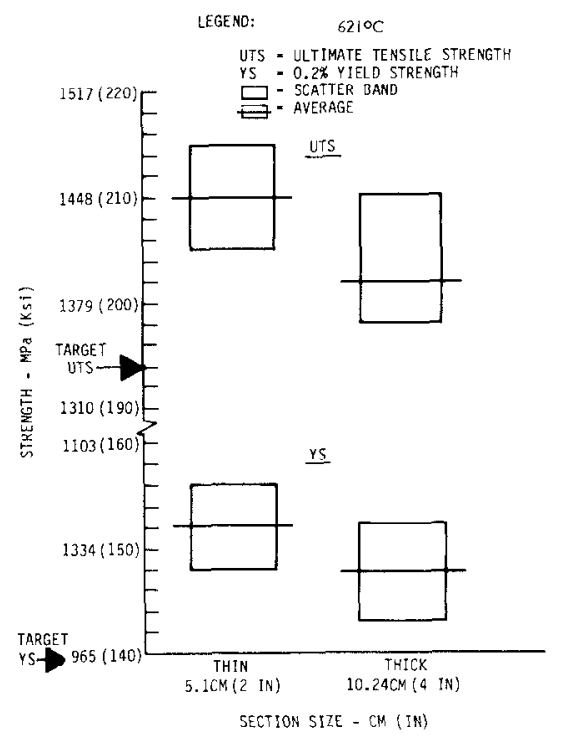

Fig. 8 Tensile Properties of Thin and Thick Sections

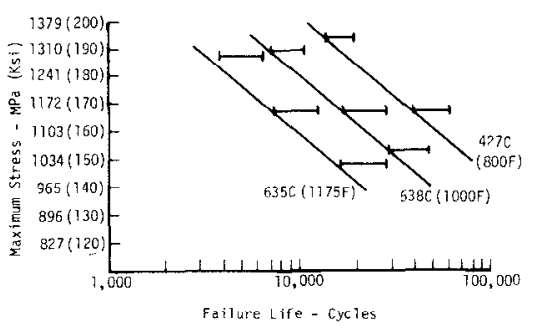

Fig. 9 Sonntag LCF Results for Smooth $\left(\mathrm{K}_{\mathrm{t}}=\right.$ 1.0) Specimens Tested at $427^{\circ} \mathrm{C}-635^{\circ} \mathrm{C}$

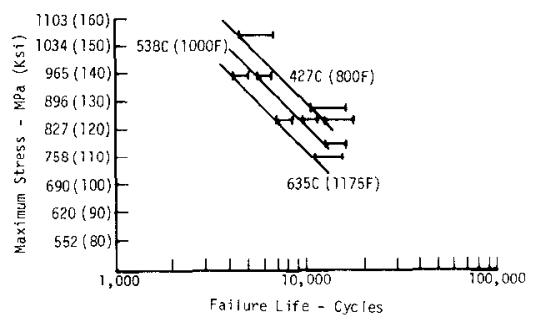

Fig. 10 Sonntag LCF Results for Notched $\left(\mathrm{K}_{\mathrm{t}}=\right.$ 2.0) Specimens Tested at $427^{\circ} \mathrm{C}-635^{\circ} \mathrm{C}$

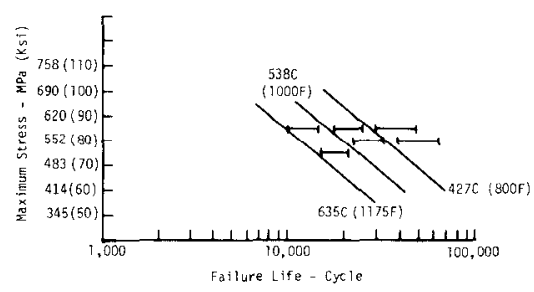

Fig. 11 Sonntag LCF Results for Notched $\left(\mathrm{K}_{\mathrm{t}}=\right.$ 3.0) Specimens Tested at $427^{\circ} \mathrm{C}-635^{\circ} \mathrm{C}$ 


\section{CONCLUSIONS}

1. Manufacturing experience gained on full-size MERL 76 disk consolidations indicates that powder handling and HIP processing methods are adequate for producing disks for use in advanced gas turbine engines.

2. A multi-step heat treatment for MERL 76 has been selected $1163^{\circ} \mathrm{C} / 2$ hours $/ \mathrm{OQ}+871^{\circ} \mathrm{C} / .67$ hours $+992^{\circ} \mathrm{C} / .75$ hours $/ \mathrm{AC}+649^{\circ} \mathrm{C} / 16$ hours $/ \mathrm{AC}+760^{\circ} \mathrm{C} / 24$ hours $/ \mathrm{AC}$.

3. Based on tensile, stress-rupture, and Sonntag LCF testing of material removed from various locations of fullsize disk components, the MERL 76 alloy has met all target goals.

4. Improved specifications and qualification procedures are necessary to ensure use of powder free of the type of contamination cited in this work.

\section{REFERENCES}

1. M. J. Blackburn and R. A. Sprague, Metals Technology, August 1977, pp. 388-395.

2. P. S. Mathur and J. L. Bartos, U.S. Army Contract DAAJ02-73-C-0106, Report No. USA RTL-TR-78-56, Supplemental Final Report for period 1976-1978, April 1979.

3. R. D. Eng and D. J. Evans, Materials for Advanced Turbine Engines Project 1, NASA Contract NAS3-20072, Report No. CR-135409, March 1978.

\section{AKNOWLEDGMENT}

The authors wish to acknowledge the assistance of Mr. R. L. Davies of the National Aeronautical Space Administration for his invaluable consultation and direction in this program which was partially supported by the National Aeronautical Space Administration under contract NAS3-20072. 